Jens Börstinghaus

\title{
Sturmfahrt und Schiffbruch
}

Zur lukanischen Verwendung eines literarischen Topos in Apostelgeschichte 27,128,6

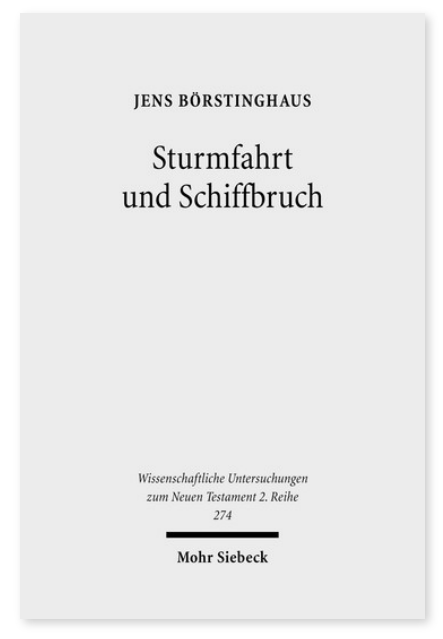

2010. XVIII, 554 Seiten. WUNT II 274

ISBN 978-3-16-151617-7

DOI 10.1628/978-3-16-151617-7

eBook PDF $119,00 €$

ISBN 978-3-16-149996-8

fadengeheftete Broschur 119,00€
Vor dem Hintergrund eines ausführlichen Vergleichs mit ausgewählten antiken Sturm- und Schiffbruchserzählungen untersucht Jens Börstinghaus die große lukanische Erzählung Apg 27,1-28,6, in der Paulus bis nach Malta gelangt. Besondere Bedeutung kommt dieser Erzählung deswegen zu, weil sie den Abschluß des gesamten lukanischen Doppelwerks fulminant vorbereitet. Lukas erweist sich dabei nicht gerade als begnadeter Literat, aber sehr wohl als engagierter und selbständiger frühchristlicher Schriftsteller, der seinen Adressaten mit dem durch alle Gefahren und Bedrängnisse hindurch nach Rom gelangenden Paulus eine attraktive Identifikationsfigur anbietet. Die vorrangig an der literarischen Motivik orientierte Studie leistet aber nicht nur einen Beitrag zum lukanischen Paulusbild, sondern darüber hinaus sowohl zur Frage nach der Gattung der Apostelgeschichte als auch zu dem noch immer umstrittenen Problem der sog. »Wir« - Stücke.

Jens Börstinghaus Geboren 1972; Studium der Ev. Theologie und Griechischen Philologie in Greifswald und Heidelberg; 20022003 Wiss. Mitarbeiter an der Theologischen Fakultät Greifswald; 2003-2004 Promotionsstipendiat der Studienstiftung des deutschen Volkes; seit 2004 Wiss. Mitarbeiter am Lehrstuhl für Neues Testament I in Erlangen; 2008 Promotion.
Jetzt bestellen:

https://mohrsiebeck.com/buch/sturmfahrt-und-schiffbruch-9783161516177?no_cache=1

order@mohrsiebeck.com

Telefon: +49 (0)7071-923-17

Telefax: +49(0)7071-51104 